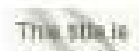
now indered in Scopse

atisticas

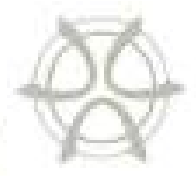

PLANNING MAL AYSIA

Geospanial Analysir in Urban Planning

Volume II (2013). Page 23 - 38

\title{
ESTIMATION OF RESIDENTIAL IMPERVIOUS SURFACE USING GIS TECHNIQUE
}

\author{
M. Rafee Majid', Jamal Aimi Jamaludin ${ }^{2} \&$ Wan Yusryzal Wan Ibrahim ${ }^{3}$ \\ ${ }^{1,268}$ Centre for Innovative Planning and Development (CiPD) \\ Faculty of Built Enviromnent \\ UNIVERSITI TEKNOLOGI MALAYSIA
}

\begin{abstract}
Urban impervious surface in the form of rooftops, street pavement, parking lots; etc. is an important contributor to water pollution, urban heat island, flash floods and other environmental degradations. While studies on the extent of impervious surface are common in advanced countries, few have been carried out in developing countries. This paper discusses a study on the nature of impervious surface coverage in a southern city in Malaysia. The study focuses on impervious surface in several residential areas, looking at the relationship between impervious surface and housing density as well as the source of the surface. Remote sensing images combined with some GIS techniques were employed for this purpose. The percentage of impervious surface measured ranged from $40-95 \%$, well above the values indicated from similar studies overseas. While density was a factor in the amount of impervious surface, it was not the only factor. Other factors such as policies on impervious surface control were also important as illustrated by comparison of the results of this study to similar studies reported in the USA. Based on these findings, the paper offers several steps towards reduction of impervious surface in residential areas.
\end{abstract}

Keywords: Impervious surface, remote sensing, GIS, residential imperviousness.

\footnotetext{
${ }^{3}$ Aswociate Protessor at Deportmerk of Urban and Regional Planninz Faculty of Built Envircnenent, Universiti Tébologi Malaysia. Emaili rafeod utm.my (Correspondirg Auboo)
} 


\section{INTRODUCTION}

Any material covering the ground that prevents infiltration of water into the soil can be classified as an impervious surface (Arnold \& Gibbons 1996). While it is not a single homogeneous quantity, when impervious surface is used as a landscape indicator it is typically presented as a percentage of the land that is covered with impervious materials. The word imperviousness is also regularly used to refer to the extent of this pereentage.

Impervious surfaces come in different types such as paved surfaces (roads, parking lots, sidewalks, etc.) and building rooftops that fall unambiguously under the definition of impervious surface. Yet there are also traditionally pervious surfaces, man-made and natural, that are so heavily compacted that they become functionally impervious. Examples of these are compacted soil in construction areas, dirt rosds, bedrock outcrops and, even to a certain extent, grass turf in our residential areas. This paper, however, focuses on the earlier category of impervious surfaces, i.e. paved surfices and building rooftops.

It is a fact that urbanisation carries with it a series of envirommental concems such as water and air pollution as well as increase in temperature and occurrence of flash floods. On many occasions have these been linked to the extent of impervious surface, an indicator that defines urtanisation. As development alters the natural landscape, the percentage of land covered by impervious surface also alters, i.e, it increases. Increase in urban impervious surface has been identified by many studies as an important contributor to a host of urban problems including water pollution, urban heat island, flash floods and other environmental degradations (Hammer 1972; Booth 1991; Schueler 1994; Amold \& Gibbons 1996).

While studies on the extent of impervious surface are common in advanced countries, only a few have been carried out in developing countries. Lacking empirical local values, guidelines or manuals requiring the use of impervious surface estimate simply adopts values from overseas such as the case of Manual Saliran Mesra Alam or MSMA adopting values from Australia (MSMA 2012). The justification for such action comes into question given our different approach towards development. In view of that, this paper discusses a study on the nature of impervious surface coverage in Johor Bahru, Malaysia. The study focuses on impervious surface in several residential areas, looking at the relationship between impervious surface and housing density as well as the 
source of the surface. Remote sensing images combined with GIS techniques were employed for this purpose.

\section{IMPERVIOUS SURFACE IN HOUSING AREAS}

There have been very few studies (if any) on the amount of impervious surface per unit urban area in Malaysia, even though impervious surface has been recognised as an important indicator of urbanisation and its associated impact on the environment. The parameters concerning impervious surface that have been adopted for local uses, in runoff estimation for example, are those from developed countries such as Australia and the USA. One example of empirical values obtained from overseas is those reported by the Soil Conservation Services (SCS) in the USA listed in Table 1. The validity of such values for usage in Malaysia is however questionable due to several factors. Our more compact housing areas would in theory lead to higher percentage of impervious surface per unit area. The maximum density of single-family housing in Malaysia which can reach up to 30 units per acre, for example, is much more than the maximum depicted in the table. Other factors such as building design, street standards, and subdivision regulations are also different from those in the USA and would definitely influence the amount of impervious surface. Thus, it has been long overdue that we know exactly the extent of our impervious surface and its relationship to urbanisation.

Tabie 1: Impervicus surface according to urban land use (SCS, USA)

\begin{tabular}{|l|c|}
\hline Urbaa Land Use & Average Impervious Surlace (\%) \\
\hline Commercial Areat & 85 \\
Industrial Area & 72 \\
& \\
Housing Area (According to Density): & 65 \\
\hline 8 units/acres or more & 38 \\
4 units/acres & 30 \\
3 units/acres & 25 \\
2 units/actes & 20 \\
1 units/acres & 12 \\
$1 / 2$ units'actes & \\
\hline
\end{tabular}

The relationships between the characteristics of housing areas, particularly density and design, and the amount of impervious surface have been studied extensively in developed countries (see Majid 2005; Stone Jr. 2004; Capeilla \& Brown 2001). Majid (2005), for instance, showed that the amount of impervious surface was correlated to density and design in a non-linear manner 
(Figure 1). The gross densities calculated in his study were however relatively low compared to what is prevalent in Malaysia, i.e. 0.5-6 units/acre in contrast to about 4-30 units/acre in Malaysia. Thus the impervious surface percentage of between $10-40 \%$ reported by him would be well below what is expected for housing areas in Malaysia whose densities are higher.

In addition to density, the design of housing layout also plays an important role in determining the amount of impervious surface. In the same study, Majid (2005) also reported that conventional layouts (where the whole development parcelled out into individual housing lots) resulted in higher imperviousness than cluster layouts (conservation layouts that leave some open space for conservation). The difference in imperviousness level between the two layout types is shown in Figure 1 while Figure 2 highlights the many advantages of a cluster layout over a conventional one. Though originally promoted for conservation of critical open spaces, cluster layouts have lately been promoted more as an alternative design to reduce imperviousness (Arnold \& Gibbons 1996; Schueler 1996; Arendt 1996).

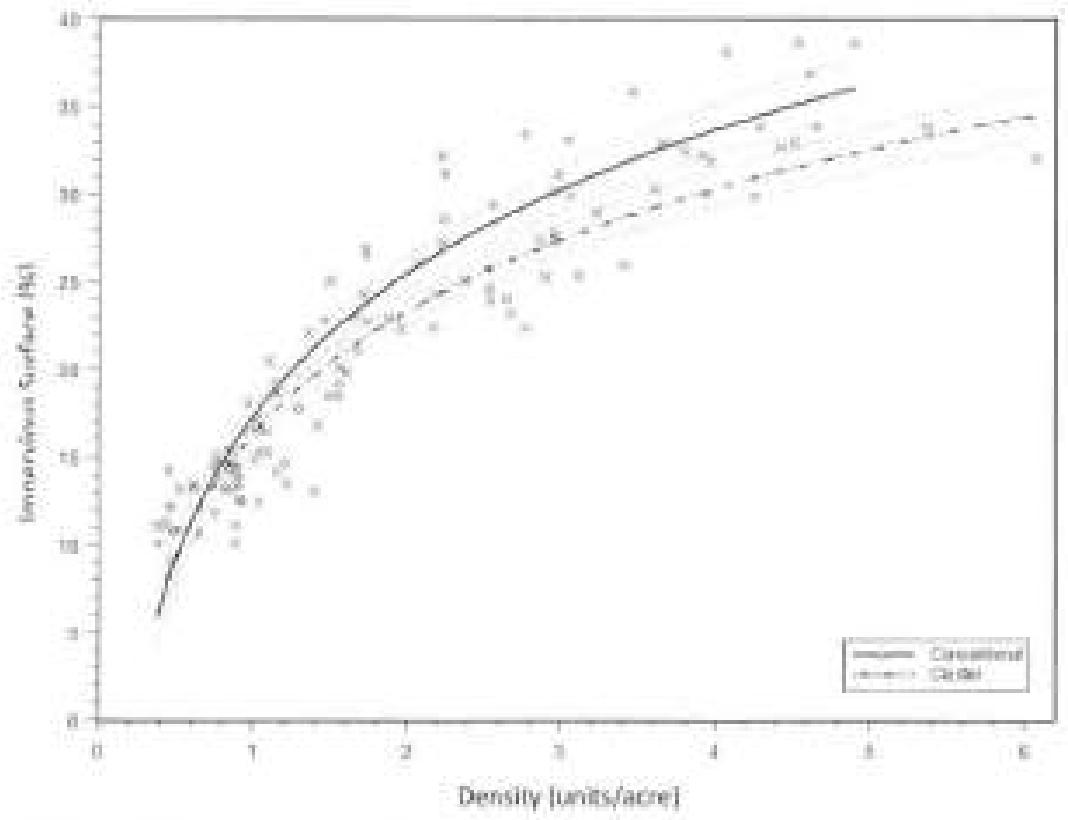

Figure 1: Impervious surface vs bousing density in North Carolina, USA 
Depending on lot size and the road network, Schueler (1996) elaims that cluster development can potentially reduce site imperviousness by as much as $10-50 \%$. In density-neutral provision for cluster development, a developer is still committed to the total units as in conventional development but has the flexibility to place them in a way that is more responsive to the physical characteristics of the site. In spite of more open space, density is maintained by allowing smaller lots than the conventional developments. Smaller lot size that results in narrower and shallower lots also helps reduce the lineal length of streets and total length of driveways. Clustering lots closer together also results in shotter roads.

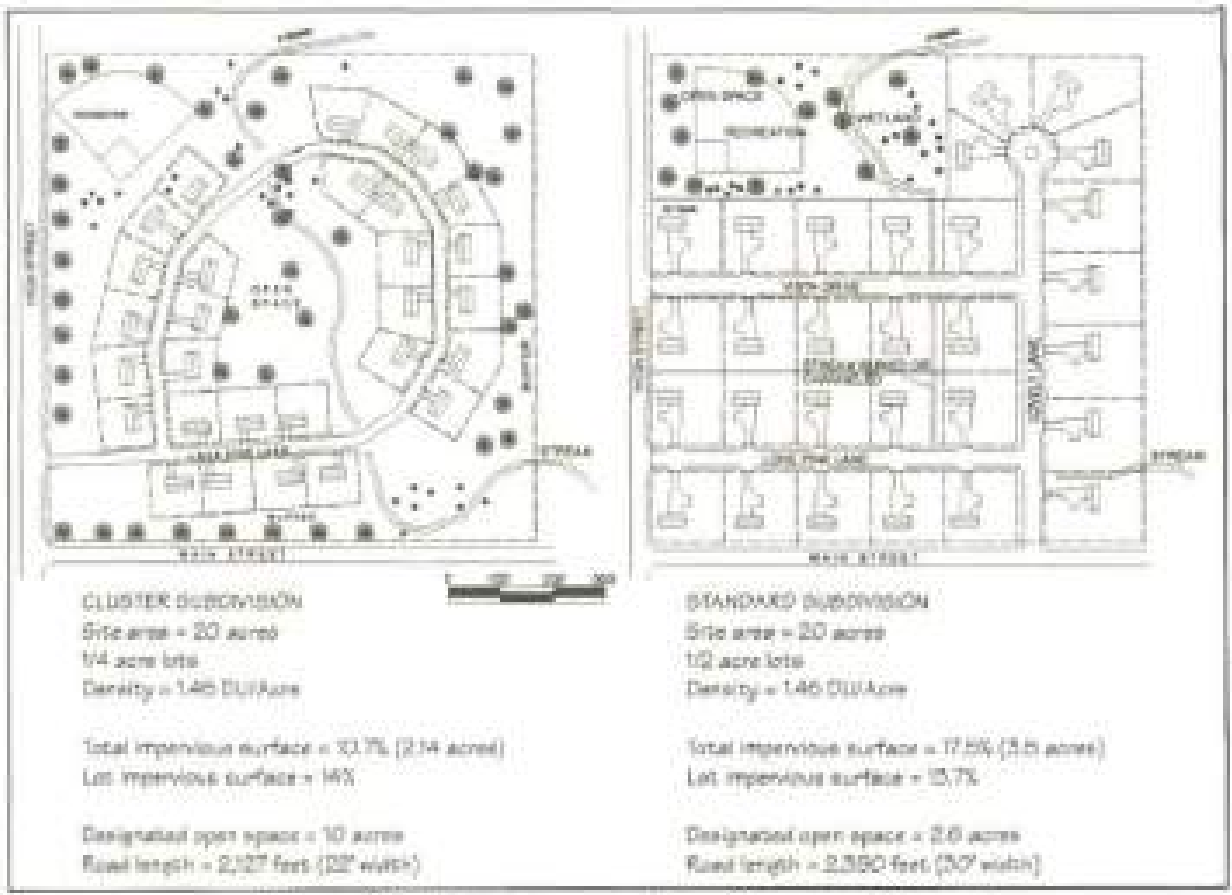

Figure 2: Cluster vs conventional (standard) layoui

S.wne: Armint \& Gidvous 1906

Cluster housing layout as practised in the United States (Figure 2), however, is rare in Malaysia. Without specific regulations requiring it, housing developers in Malaysia are more content to turn the whole development into housing or commercial lots, leaving only $10 \%$ of the area for open space as required by law. Even for the conventional layouts, there are still vast differences between housing layouts in Malaysia and those in developed 
countries, Different street designs, for example, might contribute to the difference in the overall impervious surface amount. In addition to that, a peculiar Malaysian penchant for paved compound around their houses, that is to a certain extent encouraged by lack of specific regulations concerning impervious surface limits, does also contribute to the amount of impervious surface.

\section{REMOTE SENSING AND QUANTIFICATION OF IMPERVIOUS SURFACE}

Remote sensing is a method which records the information of an object or a phenomenon on earth surface from afar by using electromagnetic wave. It is usually done through image interpretation gained from afar by using the satellite or aircraft. Most remote sensing image interpretation now uses satellite images of various brands and resolution duc to low cost and high resolution. Some of the currently popular images in accordance to resolution are AVHRR (low resolution), Landsat TM and SPOT (medium resolution), and IKONOS as well as Quickbird (high resolution).

The study of the relationship between impervious surface and land use has long begun since $1970^{\circ}$ s in the field of urban hydrology (Brabec et al. 2002). According to Brabec et al.(2002), the total size of impervious surface can be measured through four methods; 1) identifying impervious surface in the aerial photo and made measurements by using planimeter (example Stafford et al. 1974: Graham et al. 1974); 2) by placing grids on the aerial photo and count the number of squares covered by Impervious surface and other land uses (example: Gluck and MeCuen 1975; Hammer 1972; Ragan \& Jackson 1975); 3) using the method of remote sensing image classification (example: Ragan and Jackson 1975); 4) corresponding the percentage of urbanisation rate with the percentage of impervious surface (example: Morisawa \& LaFlure 1979). Several studies atso show that there is a significant difference between the relationship of impervious surface percentage and demographic factors including population density, household size and number of job opportunities (Stankowski 1972; Graham et al. 1974; Gluck \& MeCuen 1975). However, these studies depend solely on the study areas chosen, and are unsuitable to be implemented for all urban areas.

The early mapping of impervicus surface by using remote sensing images has begun by interpreting visual aerial photos but this method is complicated and time consuming when a large aren is involved. Besides, the 
manual method is subject to a high tendency of human error, even by skilled personnel. The aerial photos are also taken on different dates and scales, which need further rectification, digitation and time consuming interpretation. The establishment of Landsat Multispectral Sensor Satellite in year 1972 has provided the digital satellite image world with full view of the earth surface. By using these images, exclusive computer programs and impervious surface measurement through spectral analysis method begin to produce outputs comparable to that of the manual method - within a shorter time (Ragan \& Jackson 1975).

Compared to aerial photo, remote sensing images covers a larger area and produce a more consistent output - which can also be used in GIS. After the classification procedure has been determined for a certain image, all the remaining images shall be classified using the same procedure in a shorter amount of time, as compared to the manual method. Other special attribute of remote sensing image is that is has spectral wires which resembles various types of land cover spectral reflectance. For instance, the Landsat TM Image has six (6) spectral wires, comparing to coloured aerial photos - which only have three (3), and black and white aerial phovos - which only have one (1).

The weakness of remote sensing image is its large pixel size for certain cheap images; Landsat TM with $30 \mathrm{~m} \times 30 \mathrm{~m}$ pixel, for instance. However, there are expensive small pixel images such as IKONOS ( $4 \mathrm{~m} \times 4 \mathrm{~m}$ for multispectral, $1 \mathrm{~m} \times 1 \mathrm{~m}$ for panchromatic), Quickbird ( $2.4 \mathrm{~m} \times 2.4 \mathrm{~m}$ for multispectral, $60 \mathrm{~cm} \times$ $60 \mathrm{~cm}$ for panchromatic), Geocye-1 $(1.65 \mathrm{~m} \times 1.65 \mathrm{~m}$ for colour and $0.41 \mathrm{~m} \times$ $0.41 \mathrm{~m}$ for black \& white) and Worldview-2 $(0.46 \mathrm{~m} \times 0.46 \mathrm{~m}$ for panchromatic images). Large sum of monetary cost would be required if used on a wide area by using these high resolution images because it implicates a large number of images to be produced. For the current study, Quickbird Image shall be employed for the area of Johor Bahru Tengah Municipality (MPJBT) and Kulai Jaya Municipality (MPKJ).

The earlier method of impervious surface measurement using spectral information from remote sensing images are classification method and other clustering, thresholding and modelling methods (see Wu and Murray 2002; Rashed et al. 2003). The outputs are usually presented in the form of maps which shows the existence of impervious surfaces in certain pixels. Forster (1985) reminded about the inaccuracy of this method due to the large pixel size in representing a land use or, it is impossible for a whole area to be covered with impervious surface, and vice versa. However, this statement was done based on the pixel size of Landsat TM image, which is known to be large ( $30 \mathrm{~m}$ 
$x 30 \mathrm{~m}$ ). The current high resolution satellite images such as IKONOS and Quickbird will produce a more accurate output by using the same method. The current methods are used for the purpose of improving this weakness by combining machine learning algorithms and spectral mixture analysis to get impervious surface at the sub-pixel levels. This method is more accurate and has been proven by Flanagan \& Civco (2001), Wang et al. (2000), Ji \& Jenson (1999), Wu \& Murray (2002), Ward et al. (2000), Rashed et al. (2003) and Yang et al. (2003). Based on the early visual checks, it shows that the content of impervious surface in the study is high. Hence, the current study shall employ the method of classification based on pixel; not sub-pixel for the purpose of impervious surface measurement. The high content of impervious surface and high resolution images used has been predicted to be able to provide accurate information on the real content of impervious surface in a certain housing area.

\section{ESTIMATION OF IMPERVIOUS SURFACE AREA}

Motivated by the lack of specific information on the amount of impervious surface in urban housing areas in Malaysia and the desire to compare this amount to those reported by studies carried out in other countries, the authors set out the study with the following objectives: 1) to quantify the amount of impervious surface in urban housing areas in Malaysia using remote sensing images (Quickbird images); 2) to establish the relationship between the amount of impervious surface as the dependent variable and density of housing as the explanatory or independent variable; and 3) fo compare the extent of residential imperviousness in Malaysia to those in other countries.

The study was carried out through the following four steps:

Step 1: Identifying residential areas with different densities to measure the total size of impervious surfice;

Step 2: Processing Quickbird Satellite Images by integrating various remote sensing techniques with GIS in order to calculate the total size of impervious surface;

Step 3: Generating a regression model, which is able to forecast the total size of impervious surface based on the densities of the residential areas; and

Step 4: Recommending policies and planning guidelines which are able to minimize the total size of impervious surface. The following section introduces the study area and discusses the detailed steps involved. 


\section{Study area}

Since the study was to investigate the percentage of impervious surface in housing areas, its unit of analysis was urban housing areas located in two municipalities in the southern part of Johor. The two municipalities were Johor Bahru Tengah Municipality and Kulai Jaya Municipality. Johor Bahru Tengah Municipality covers an area of $339 \mathrm{~km}^{2}$ with a population of roughly 525,351 while Kulai Jaya Municipality has a population of 130,000 within an area of $747 \mathrm{~km}^{2}$. A total of 11 housing areas were randomly selected for the study and Figure 3 below shows their locations. The housing areas come in various sizes from as small as a few hundred acres to as large as elose to a thousand acres. The age of the housing areas varies from as old as 30 years (Taman Jaya, Taman Aman) to ats young as less than 10 years (Taman Pulai Emas, Taman Pulai Jaya). The gross density of each housing area too varies but what is of interest here is the density of each housing type which would in the end determine the amount of impervious surface.

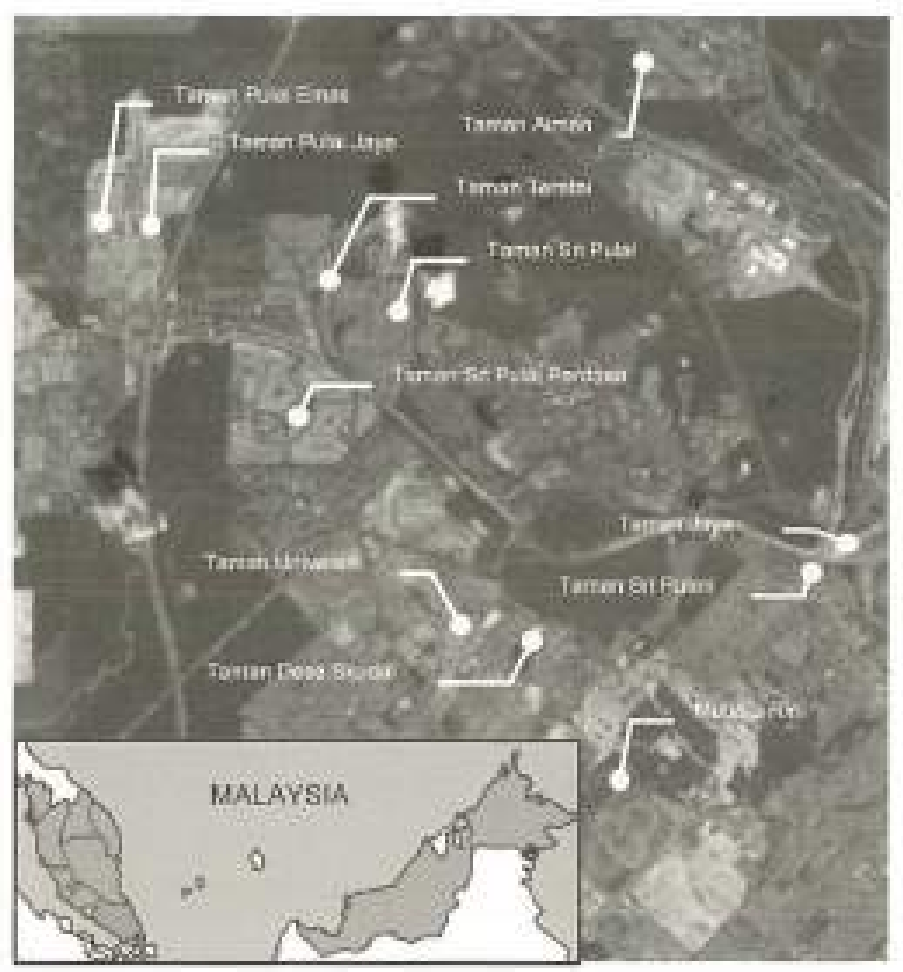

Figure 3: Study Area Showing Sampled Housing Estates 


\section{Data and Image Processing}

The study used two forms of raw data, i.e. QuickBird $0.6 \mathrm{~m}$ remote sensing images of the study area and digital layout plans delineating the housing lots and boundaries of the housing areas. All of the processing work was done on ERDAS Imagine and ArcGIS 9.2. Pre-processing of the satellite images using a geometric correction technique was first earried out on the images before they could be used. Rectification of the satellite images to the local coordinates, Rectified Skewed Orthomorphic (RSO) coordinates, was carried out with the help of a GPS receiver for collection of ground control points within the study area.

The following stage involved classification of the images in order to distinguish impervious surfaces from previous ones. The classification process involved both unsupervised and supervised classifications. The results of the classification process were classified images that had only two types of land surfaces, i.e. impervious and pervious surfaces. The classified raster images were then converted into vector format in ArcGIS 9.2 for quantification of the amount of impervious surface. In order to do this, the vectorised classified images were overlaid with the digital layout plan before the images for each of the II housing areas were clipped out. Figure 4 shows one such housing area with the impervious and pervious surfaces classified.

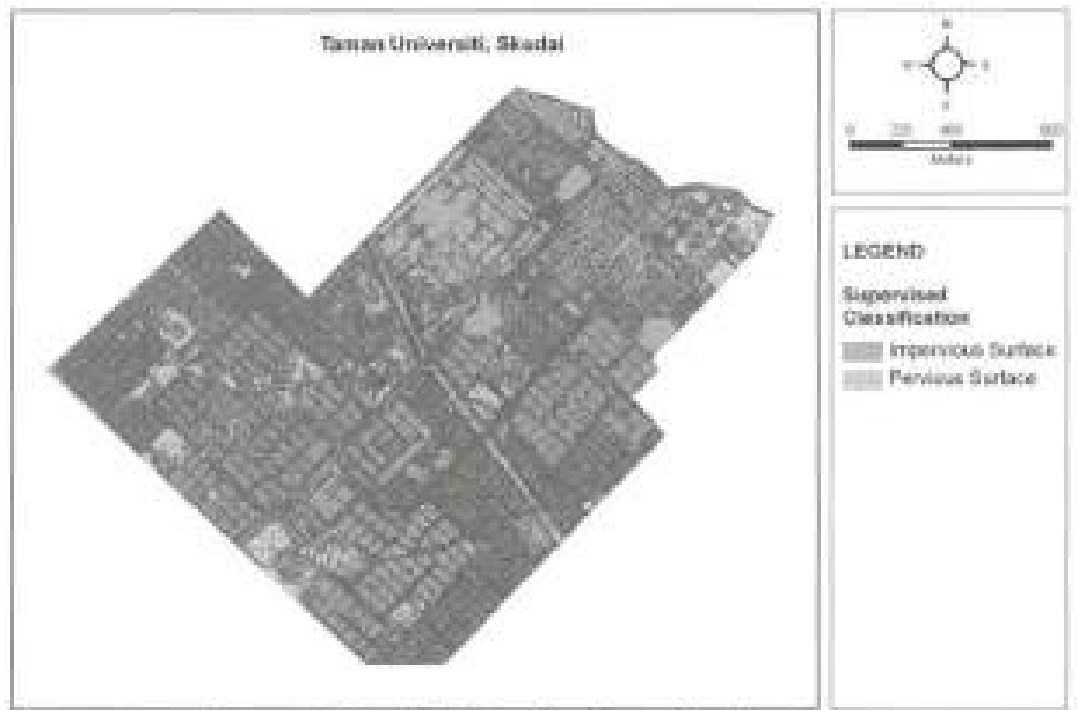

Figure 4: Classified Surface for a Housing Area 
The trend of urban housing development in Malaysia is that each housing area or estate would have a mixture of houses built in zones differentiated by house types. Thus, in a housing estate one would normally find bungalows in a zone separated from semi-detached (semi-D or duplex) houses which are in their own zone separated from terraced (linked) houses and so on. In order to capture the whole range of housing densities, the study made use of these existing housing categories for sampling of house groups to calculate the amount of impervious surface. Figures 5 shows typical house types in Malaysian housing estates. A total of 28 housing samples from the selected housing estates were randomly chosen for analysis. For each of these housing samples, the percentage of impervious surface was computed using zonal summary technique of AreGIS 9.2 .

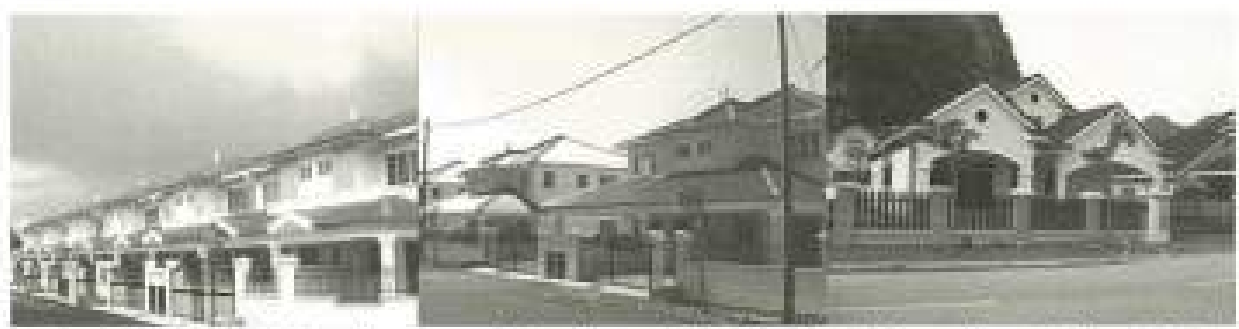

Figure 5: Typieal housing types: linked, semi-detacbed and bungalows (left to right)

\section{RESULTS AND DISCUSSIONS}

The ensuing discussion will highlight the relationship between degree of imperviousness and housing density. Before looking into the relationship between the two variables, however, it is appropriate that we look at the basic statistics of the variables collected in the study areas. This will give us an overview of the characteristics of the housing areas studied, especially those concerning intensity of development and impervious surface.

For the three housing types that are the subject of this study, Table 2 gives the details of their densities. In general, densities of the houses cover quite a range from as low as 3 units per acre for bungalows to as high as 30 units per acre for linked houses. These densities seem to double from one type to another of higher density. The mean density of linked houses, for example, is twice that of the semi-detached houses which itself is about twice the mean density of the bungalows. Overall, it is evident that housing densities in Malaysia are much higher than those in the developed countries where previous studies on impervious surface had been carried out (see Stone 2004; Majid 2005; Capeilla 
\& Brown 2001). Bungalows and semi-detached in the USA, for instance, are built in densities of 2-3 and 4-6 units per acre respectively. It is difficult to find the density of linked bouses in the USA as this type of housing is not popular there.

Table 2: Statistics of densily and impervious surface of housing types

\begin{tabular}{|c|c|c|c|c|c|c|}
\hline \multirow[b]{2}{*}{ Statistic } & \multicolumn{3}{|c|}{ Deasity (unitsjucre) } & \multicolumn{3}{|c|}{ Impervinus Surface ( $\%$ ) } \\
\hline & Bungslow & $\begin{array}{c}\text { Semi- } \\
\text { Detached }\end{array}$ & Linked & Bungalow & $\begin{array}{c}\text { Semi- } \\
\text { Detached }\end{array}$ & Linked \\
\hline Mintimum & 3.0 & 6.0 & 14.0 & 40.4 & 51.4 & 60.8 \\
\hline Maximum & 10.8 & 15.0 & 30,0 & 96,6 & 93.4 & 99.2 \\
\hline Mean & 5.9 & 10.4 & 193 & 69.4 & 76,9 & 88.2 \\
\hline Median & 5.3 & 10,0 & 19.5 & 70.4 & 79.0 & $\$ 9.8$ \\
\hline Std Devi & 2.9 & 2.9 & 4,6 & 34.1 & 14.1 & 8.9 \\
\hline Sample $\{n\}$ & 4 & 3 & 17 & 4 & 7 & 17 \\
\hline
\end{tabular}

Table 2.0 also includes the statistical summary of the percentage of impervious surface for each housing type. They range from as low as $40 \%$ for bungalows to as bigh as $99 \%$ for linked houses. As expected, the higher the density the more the impervious surface. The linked houses have the highest impervious surface percentage that ranges from the minimum of $61 \%$ to the maximum of almost $100 \%$, with the mean of $88 \%$. Given the density of this kind of housing that can go up to 30 single-family units per acre, the high percentage of impervious surface is expected. What is not expected is the high percentage of impervious surface for the bungalows. At the mean density of 6 units per acre, the mean impervious surface percentage of these bungalow areas are at $69 \%$ which exactly doubles the impervious surface percentage of American bungalows at the same density (See Figure 1).

Among the factors that contribute to the higher percentage of impervious surface in Malaysia are the road design standards that allow for excessive pavement, the practice of converting green compounds into paved ones by some house owners and of course, since we are comparing to overseas planning regulations, lack of regulations in Malaysia that set the limits on the percentage of impervious surface. Of the two major components of impervious surface studied, rooftops made up on average $70 \%$ of the total amount of impervious surface while road pavement made up 25\%. The remaining $5 \%$ consisted of driveways, footpath, etc.

Figure 6.0 plots the relationship between imperviousness and density. The nonlineat fitted curve shows how impervious surface increases rather dramatically from density of I unit/acre to 10 units/acre and then starts to taper 
off from there on to about $90 \%$. Ninety percent is the ultimate impervious surface percentage due to the regulations in Malaysia that require $10 \%$ of housing areas should be open spaces, and open spaces in most cases in Malaysia mean green vegetation. Comparing the curve of Figure 6(a) to that of Figure 1 for the same density range showcases a contrast in term of how impervious surface predominates the housing landscape in Malaysia. It is no wonder that some of these bousing estates are experiencing various environmental consequences brought about by this style of urban development. Among the environmental consequences are urban beat island, water quality deterionation, flash floods and transformation of beautiful natural streams into disgraceful urban conctete drains.
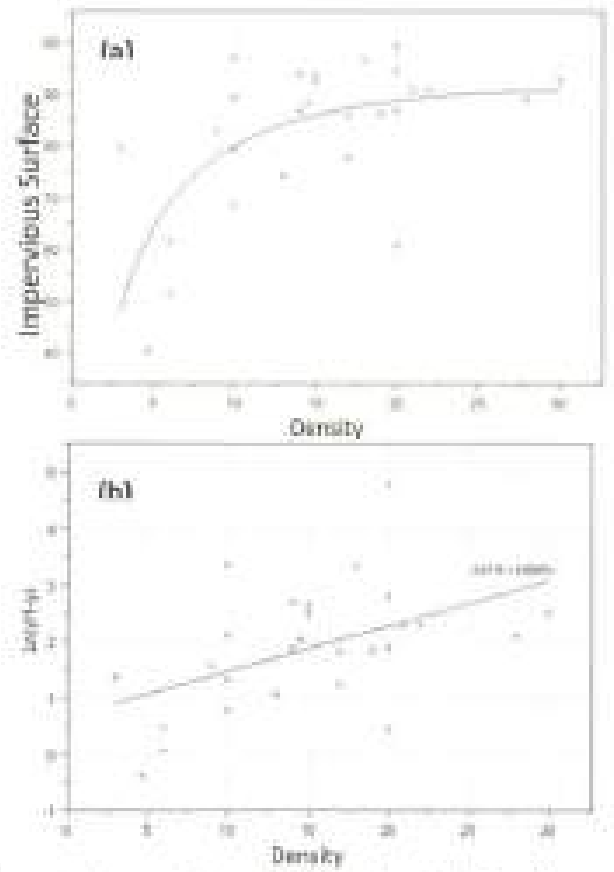

Figure 6: Impervious surfice vs density: (a) Nonlineur; (b) Linear

Logit transformation of the dependent variable in the relationship gives us the linear regression model of the percentage of impervious surface and bousing density. The linear model is given by

$\ln (y /(1-y))=0.6716+0.08 x$

where: 
$y=$ proportion of impervious surface.

$\mathrm{x}=$ housing density (units/acre)

Statistical tests indicate that the relationship is significant ( $\mathrm{p}<0.01)$ with a rather low multiple R-squared of 0.25 .

The results of the study show that impervious surface is directly correlated to density. This confirms the trend observed overseas. What is more important in this study is the fact that the amount of impervious surface in our housing areas is relatively too high. Too high that it causes a lot of environmental problems previously alluded to in the beginning of the paper. The amount of impervious surface calculated, $40-90 \%$, cannot sustain any form of lives in the streams as studies by various researchers (Schueler \& Claytor 1997; Booth 1991: Booth \& Jackson 1997) have shown that watershed with impervious surface between 20$60 \%$ will kill the stream.

\section{CONCLUSIONS}

Reducing the amount of impervious surface would be easy if only the authority were determined enough to do so. There are several ways to achieving lower impervious surface. Among them are: 1) imposing a limit on the percentage of impervious surface per subdivisional lots or per development; 2) reviewing of existing road standards that are outdated and very generous on pavement skinny streets are now the trend; 3 ) encouraging more cluster development and vertical density - the two types of development that would have any chance of conserving the enviromentally sensitive areas while being neutral on density (Richards, Anderson and Santore 2003); 4) regulating renovation of the houses - renovation that increases the amount of impervious surface within a lot should be tightly regulated; and 5) more usage of porous materials for pavement or interlocking blocks that encourage water infiltration. There are of course numerous other steps to either reduce the amount of impervious surfice or to reduce the impact of impervious surface.

\section{ACKNOWLEDGEMENT}

The author acknowledges the funding support for this research provided by the Ministry of Higher Education, Malaysia through Universiti Teknologi Malaysia under the Fundamental Research Grant (FRGS) Programme (Vot78161). 


\section{REFERENCES}

Arendt, R.G. (1996). Conservation Design for Subdivisions: A practical guide for creating open spoce networks. Island Press, Washington DC. 184pp.

Arnold, C.L. and C. J. Gibbons. (1996). Impervious surface: The emergence of a key urban environmental indicator. Journal of the American Planning Association 62(2): 243-258.

Booth, D.B. (1991). Urbanisation and the natural drainage system-impacts, solutions and prognoses. Northwest Environmental Journal 7(1):93-118.

Booth, D.B. and C.R. Jackson. (1997). Urbanisation of aquatic systems: Degradation thresholds, stormwater detention and the limits of mitigation. Journal of American Water Resources Association 33(5):1077-1090.

Brabec, E., S. Schulte and P.L. Richards. (2002). Impervious surfaces and water quality: A review of current literature and its implications for watershed planning. Journal of Planning Literature 16(4):499-514.

Cappeilla, K. and K. Brown. (2001). Land use and impervious cover in the Chesapeake Bay region. Watershed Protection Techiniques 3(4):835-840.

Flanagan, M., and D.L Civeo. (2001). Subpixel impervious surface mapping. Proceedings of the 200I ASPRS Annual Convention, 23-27 Apr, 2001, St. Louis, MO.

Forster, B.C., (1985). An examination of some problems and solutions in monitoring urban areas from satellite platforms. International Journal of Remote Sensing 6(1):139-151.

Gluck, W.R. and R.H. McCuen. (1975), Estimating land use characteristics for hydrologic models. Water Rexaurces Research 1 I(1):177-179.

Graham, P.H. S.C. Lawrence and H.J. Mallon. (1974). Estimation of imperviousness and specific eurb length for forecasting stormwater quality and quantity. Journat of the Water Pollution Controt Federation 46(4):717-725.

Hammer, T.R. (1972). Stream enlargement due to urbanisation. Water Resources Bullefin 8(6): $1530-1540$.

Majid, M. Rafec. (2005). Residential Impervioasnexs: Potential Usage of Remote Sensing and Evaluating the Inflaeaces of Density and Subdivision Designs. Unpublished PhD Dissertation. Univ, of North Carolina. Chapel Hill, NC.

Morisawa, M. and E. LaFlure, (1979). Hydraulic geometry, stream equilibrium and urbanisation. In Adjustments of the fluvial systems - Procedings of the $10^{\mathrm{h}}$ Annual geonorphology Sympasium Series. D.D. Rhodes and G.P. Williams (eds.). Binghamton, NY.

MSMA or Manual Saliran Mesra Alam. (2012). 2nd Edition. Department of Irrigation and Drainage. Percetakan Nasional Berhad.

Ragan, R.M. and TJ. Jackson. (1975). Use of satellite data in urban bydrologic models. Journal of the Hydradics Division ASCE 101: 1469-1475. 
Rashed, T., J.R. Weeks, D. Roberts, J. Rogan, and R. Powell. (2003). Measuring the physical composition of urban morphology using multiple endmember spectral mixture models. Phorogrammetric Engineering \& Renote Sensing $69(9): 1011-1020$.

Richards, L, G. Anderson and M.K. Santore. (2003). Protecting water resources with higher density developments, Proceeding of the National Conference on Urban Stormwater: Enhancing program at the Lacal Level. 17-20 February, 2003, Chicago,IL.

Schueler, T.R. (1994). The importance of imperviousness. Watershed Protection Techniquex 1(3):100-1.11.

Schueler, T.R. (1996). Site Planning for Urban Stream Protection. Center for Watershed Protection. Ellicott City, MD. Available online at http:/www.cwp.org/SPSP/TOC.htm.

Schucler, T.R. and $\mathbb{R}$. Claytor. (1997). Impervious cover as an urban stream indicator and a watershed management tool. In Effects of watershed development and management in ayuaric ecosystems: proceedings of an engineering workshop. L.,A. Roesner (ed.). ASCE, New York, pp513-529.

Stafford, D.B., J.T. Ligon and M.E. Nettles. (1974). Use of acrial photographs to measure land use changes in remote sensing and water resources management. Proceedings 17, American Water Resourzes Association. American Water Resources Association. Herndon, VA.

Stankowski, S.J. (1972). Population density as an indirect indicator of urban and suburban land-sarface modiffications. U.S. Geological Survey Professional Paper 8(X)-B. US. Geological Survey. Washington, DC.

Stone Jr., B. (2004). Paving over paradise: how land use regulations promote residential imperviousness. Landscape and Urhan Planning 69:101-113.

Wang, Y.Q., X. Zhang, and W. Lampa. (2000). Improvement of spatial accuracy in natural resources mapping using multisensor remote sensing and multisource spatial data, Proceedings of the Ath International Symposium on Spatial Accurary Assessment in Nameal Rexources and Emironmental Sciences. 12-14 July 2000. Amsterdam, The Netheriands, G.B.M. Heavelink and M.J.P. Lemmens (eds.). Delft University Press. Delft, The Netherlands. pp723-730,

Ward, D., S.R. Phinn and A.T. Murray, (2000). Monitoring growth in rapidly urbanised areas using remotely sensed data. Professional Geographer 52(3):371-86.

Wu, C. and A.T. Murruy. (2002). Estimating inpervious surfuce distribution by spectral mixture analysis. Remose Sensing of Environment 84:493-505.

Yang, L., C. Huang, C.G. Homer, B.K. Wylie and Michael J. Coan.(2003). An approach for mapping large-area impervious surfaces: synergistic use of Landsat-7 ETM+ and high spatial resolution imagery. Canadian Journal of Renote Sensing 29(2):230-240. 